Regina Celia Rodrigues da PAZ ${ }^{1}$

Rodrigo Hidalgo Friciello TEIXEIRA ${ }^{2}$

Marcelo Alcindo de Barros Vaz GUIMARÃES

Correspondência para: REGINA CELIA RODRIGUES DA PAZ

Rua Domingos Russo, n. 120 -Jd. Sandra 18031-210 - Sorocaba - SP

repaz@usp.br-

Recebido para publicação: 07/10/2004 Aprovado para publicação: 01/06/2005

\title{
Avaliação das características seminais de macacos pregos (Cebus apella) mantidos em cativeiro, antes e após vasectomia bilateral
}

\author{
1 - Departamento de Reprodução Animal da Faculdade de Medicina \\ Veterinária e Zootecnia da Universidade de São Paulo, São Paulo - SP \\ 2 - Fundação Parque Zoológico de São Paulo, São Paulo - SP
}

\section{Resumo}

Este estudo teve como objetivo avaliar os efeitos da vasectomia bilateral nas características seminais de macacos pregos (Cebus apella) mantidos em cativeiro. Foram utilizados seis animais da Fundação Parque Zoológico de São Paulo. Sêmen foi colhido por eletroejaculação, após anestesia geral dos animais. A primeira colheita foi realizada 15 dias antes da vasectomia e as colheitas posteriores foram realizadas com intervalo de 30 dias até o momento da eliminação completa de espermatozóides do líquido seminal. Imediatamente após a ejaculação, o sêmen foi avaliado quanto suas características físicas, iniciando-se pelo volume $(\mathrm{ml})$ da fração líquida e medição do $\mathrm{pH}$. Posteriormente foram avaliados motilidade (\%) e vigor espermático (0-5). Uma fração do sêmen foi diluída em formol salina $10 \%$, para posterior avaliação da concentração espermática (cel/ml) e das características morfológicas (\%). A integridade do acrossoma foi avaliada apenas na primeira colheita e a concentração espermática foi avaliada em apenas quatro animais na colheita antes da vasectomia devido ao fato de não haver quantidade suficiente de sêmen. Na primeira colheita após a vasectomia, todos os animais apresentaram espermatozóides com motilidade e vigor iguais a zero. No entanto, a concentração espermática pode ser avaliada até a segunda colheita pós-vasectomia, apresentando as Médias/EP 2.8 $\pm 1.3 \times 10^{6} / \mathrm{ml}$ antes da vasectomia e $4.7 \pm 1.6$ e $0.8 \pm 0.7$ x $10^{6} / \mathrm{ml}$, após a vasectomia, respectivamente. Apenas na terceira colheita a média da concentração espermática foi igual a zero. Os resultados sugerem que machos vasectomizados devam voltar ao grupo, sem risco de fecundação acidental, após três meses da realização da vasectomia.

\section{Introdução}

Os macacos do gênero Cebus são animais de porte médio, de hábitos arborícolas, constituição robusta e cauda preênsil. Possuem grande capacidade de adaptação e sobrevivem em diferentes tipos de ambientes ${ }^{1,2}$. A maturidade sexual pode ser estimada pelo estágio de erupção dos dentes caninos e pelo peso aproximado de 2,5 $\mathrm{kg}$ para os machos e de 1,8 $\mathrm{kg}$ para as fêmeas ${ }^{3}$. O aparelho reprodutor dos machos é composto por dois testículos escrotais, um par de vesículas seminais, próstata, um par
Palavras-chave:

Vasectomia.

Primatas.

Sêmen.

Controle populacional de glândulas bulbo-uretrais ${ }^{4}$ e um pênis que contém um vestígio de osso peniano ${ }^{5}$.

Essa espécie se adapta e reproduz muito bem em cativeiro produzindo grande número de indivíduos, já que o ciclo ovariano das fêmeas é do tipo menstrual, com duração de 18 dias $^{6,3}$, ocorrendo durante todo o ano, assim como a espermatogênese ${ }^{3}$. Segundo o CENSO da SZB de 2003, 68 instituições mantêm um total de 1015 macacos pregos (Cebus apella), sendo que somente a Fundação Parque Zoológico de São Paulo possui 87 animais ${ }^{7}$. Este fato, somado ao grande número de animais provenientes de vida livre 
que chegam aos zoológicos, torna a reprodução desta espécie em cativeiro, inviável, devido ao grande número de excedentes existentes nos zoológicos.

Frente a isso, alternativas para o controle populacional da espécie em cativeiro tornam-se emergenciais. Uma das alternativas poderia ser a orquiectomia. No entanto a utilização dessa técnica eliminaria por completo este animal de futuros programas de reprodução, podendo resultar na perda de importantes linhas genéticas. Outro aspecto a ser ressaltado quanto à utilização da orquiectomia seria a ruptura da estrutura social do grupo, gerando alterações comportamentais. O efeito da dominância sobre o comportamento sexual e a fertilidade foi demonstrado em babuínos (Papio anubis) nos trabalhos de Sapolsky e Krey ${ }^{8}$.

Neste caso, a vasectomia seria a técnica mais indicada a ser utilizada para o controle destes animais em cativeiro, já que a produção de células da série espermatogênica é mantida após a vasectomia ${ }^{9,10}$. Técnicas de reprodução assistida como Fertilização in vitro (FIV) ou Injeção Intra-citoplasmática (ICSI) poderiam ser utilizadas, através do sêmen coletado do epidídimo de machos vasectomizados.

Este estudo propõe a avaliação da eficácia da vasectomia como método de controle populacional da referida espécie em cativeiro, determinando o período após o qual ocorre a eliminação completa de espermatozóides no líquido seminal, usando a técnica de colheita de sêmen por eletroejaculação ${ }^{11}$.

\section{Materiais e Métodos}

\section{Animais}

Foram utilizados seis exemplares de macaco prego (Cebus apella), adultos, machos, de procedência indeterminada e fenótipos semelhantes. Os animais foram mantidos na Fundação Parque Zoológico de São Paulo, em recintos individuais.

\section{Eletroejaculação}

Os animais foram previamente anestesiados com auxílio de caixa de prensa, utilizando-se a associação TiletaminaZolazepan (Zoletilâ) na dose $7 \mathrm{mg} / \mathrm{kg}$, via intramuscular, em uma única injeção.

A eletroejaculação foi realizada utilizando-se aparelho para colheita de sêmen de bovinos domésticos, com controle de voltagem de 0 a 12 volts e eletrodo com $9 \mathrm{~mm}$ de diâmetro e $11 \mathrm{~cm}$ de comprimento, contendo tiras longitudinais em cobre ${ }^{7}$. A primeira colheita foi realizada 15 dias antes da vasectomia, para assegurar a presença de espermatozóides colhidos por esse método nos indivíduos a serem testados. As demais eletroejaculações foram realizadas com intervalo de trinta dias até o momento da eliminação completa de espermatozóides do líquido seminal.

\section{Vasectomia}

A vasectomia foi realizada em um corte único na linha Alba, com acesso ao cordão espermático direito e esquerdo, após pequena incisão na túnica vaginal o ducto deferente foi isolado, ligado com fio de algodão 2.0 e seccionado.

\section{Avaliação do Sêmen:}

Imediatamente após a ejaculação foram avaliadas as características físicas do ejaculado, iniciando-se pelo volume da fração líquida e medição de $\mathrm{pH}$. Uma gota desta fração foi depositada em lâmina coberta por lamínula e avaliada em Microscópio de Luz para determinação da presença ou não de espermatozóides. Havendo a presença de espermatozóides, estes foram avaliados quanto a motilidade (0-100\%) e vigor (0-5). Uma alíquota desta fração foi diluída em formol salino $10 \%$ para avaliação da concentração espermática e das características morfológicas do sêmen. A concentração espermática foi realizada com auxílio de câmara de newbauer e as características morfológicas foram avaliadas em câmara úmida pela contagem de 100 células/lâmina em Microscópio de Contraste de Fase ${ }^{12}$. Na primeira colheita um total de $3 \mathrm{ml}$ de sêmen foi depositado em 
uma lâmina, juntamente com $3 \mathrm{ml}$ de corante POPE e um esfregaço foi realizado, posteriormente 100 células/lâmina foram avaliadas em Microscópio de Contraste de Fase quanto à integridade do acrossoma ${ }^{13}$.

Determinação do Volume Testicular e Avaliação dos Testículos

O volume testicular foi determinado utilizando-se biometria testicular, com auxílio de um paquímetro. Foram aferidos comprimento e largura dos testículos direito e esquerdo e os resultados analisados segundo a fórmula $\mathrm{V}=\mathrm{C} \times \mathrm{L}^{2} \mathrm{x} 0.524$, onde $\mathrm{V}=$ volume, $\mathrm{C}=$ comprimento e $\mathrm{L}=$ largura ${ }^{14}$. Para obtenção do volume total foram somados os volumes de cada testículo. A avaliação clínica dos testículos foi realizada por palpação digital e classificados como rígido, normal ou flácido.

\section{Análise Estatística}

A média e o erro padrão do volume da fração líquida, da motilidade, do vigor, do $\mathrm{pH}$, da concentração, das anormalidades espermáticas, da integridade do acrossoma e do volume testicular foram calculadas para cada colheita. O Test $t$ de Student foi usado para analisar as diferenças entre os dados obtidos antes e após a vasectomia ${ }^{22}$.

\section{Resultados}

Não houveram problemas relacionados ao pós-operatório nos animais vasectomizados. Os animais não apresentaram sintomas inflamatórios ou infecção local, sendo o tempo de recuperação completa de 10 a 15 dias após o procedimento.

A tabela 1 mostra a Média/EP dos ejaculados quanto ao volume da fração líquida, a motilidade, o vigor, a concentração e as anormalidades espermáticas, bem como a Média/EP do volume testicular antes e após a vasectomia. Os gráficos 1 a 6 mostram o volume da fração líquida, a motilidade, o vigor, a concentração, a porcentagem de espermatozóides normais e o volume testicular individual de cada animal antes e após a vasectomia.

Imediatamente após a vasectomia, o volume do ejaculado diminuiu para a maioria dos machos, no entanto não houve diferença significativa entre as colheitas ( $p>0,05)$. O $\mathrm{pH}$ não variou durante as colheitas sendo a Média/EP encontrada nos ejaculados de $7,5 \pm 0,2$.

Antes da vasectomia, a motilidade espermática individual variou de 40 a $90 \%$ e vigor espermático individual variou de 2 a 5. No entanto, na primeira colheita, realizada um mês após a vasectomia, não foram encontrados espermatozóides vivos nos ejaculados dos machos vasectomizados.

Por outro lado, com relação à concentração espermática, não houve diferença significativa $(p>0,05)$ entre a colheita pré-vasectomia e a primeira e segunda colheitas pós-vasectomia (variação individual 0.1 a $7.8 \times 10^{6} / \mathrm{ml}$ na primeira; 0.3 a $7.8 \times 10^{6} / \mathrm{ml}$ na segunda e 0.1 a $2.3 \times$ $10^{6} / \mathrm{ml}$ na terceira colheita). Somente a partir da terceira colheita após a vasectomia podese constatar a ausência completa de espermatozóides no líquido seminal de todos os machos vasectomizados. Apenas um animal apresentou ausência completa de espermatozóides na primeira colheita após a vasectomia, dois animais apresentaram ausência completa de células espermáticas na segunda colheita e três animais apresentaram ausência completa de espermatozóides no líquido seminal apenas na terceira colheita, a qual foi confirmada por mais três colheitas com resultados negativos consecutivos.

Os machos apresentaram uma redução significativa no volume testicular na primeira e segunda colheitas $(\mathrm{p}=0.02 \mathrm{e}$ $\mathrm{p}=0.04)$. No entanto, após a terceira colheita não houve diferença significava quando comparada com a primeira colheita, realizada antes da vasectomia. Ao exame clínico os testículos apresentaram-se normais à palpação em todas as colheitas realizadas.

Também não houve diferença significativa com relação às anormalidades espermáticas antes e após a vasectomia $(\mathrm{p}>0,05)$, sendo a Média/EP total para 
espermatozóides normais de $67.2 \pm 5.1 \mathrm{e}$ para espermatozóides anormais de 32.8 5 5.2. Quanto à integridade do acrossoma a Média/EP encontrada foi de $67.4 \pm 16.3$ para o ejaculado colhido na primeira colheita, ou seja, antes da vasectomia (Fig.1).
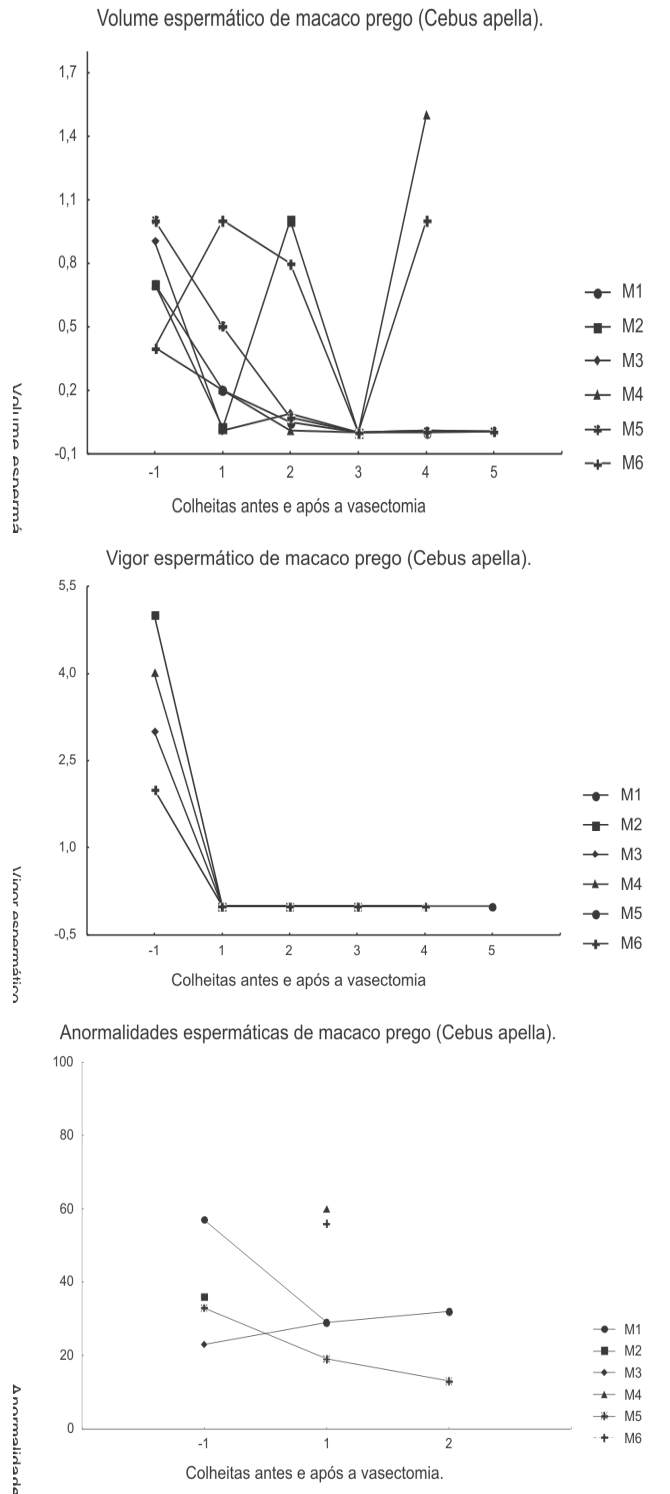

\section{Discussão}

Este ensaio estabeleceu os efeitos da vasectomia nas características seminais de macacos pregos mantidos em cativeiro.

Em trabalhos anteriores o volume de sêmen obtido para a espécie utilizando o
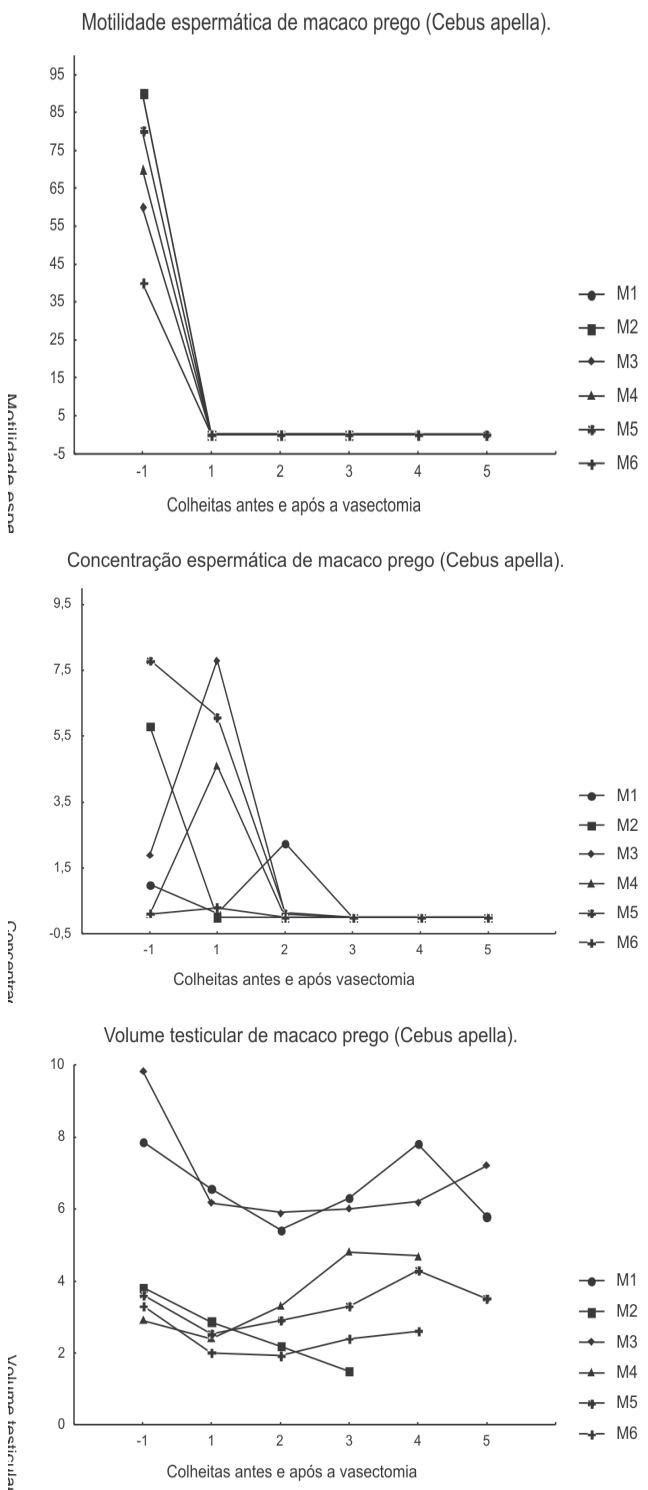

Figuras 1 a 6 - Volume, motilidade, vigor, concentração, porcentagem de espermatozóides normais e volume testicular de macacos pregos (M1 a M6) mantidosem cativeiro, antes e após vasectomia, São Paulo, 2003 
método de eletroejaculação variou de 0.5 a 1.9, a motilidade média variou de $10 \%$ a $93 \%$ e a concentração espermática variou de 56 a $740.2 \times 10^{6} / \mathrm{ml}^{16,17,11,3,18}$. Analisando estes resultados, verificamos que o volume total do ejaculado, na coleta anterior a vasectomia $(0.7 \mathrm{ml})$, bem como a motilidade (71.7\%), encontram-se próximos aos dados encontrados na literatura. Já a concentração espermática $\left(2.8 \times 10^{6} / \mathrm{ml}\right)$ encontra-se bem

Tabela 1 - Média e Erro Padrão do volume da fração líquida, motilidade, vigor, concentração e anormalidades espermáticas, integridade de acrossoma evolume testicular de macacos pregos (Cebus apella) pré e pós vasectomia, São Paulo, 2003

\begin{tabular}{|c|c|c|c|c|c|c|c|c|}
\hline Colheita & $\begin{array}{l}\text { Vol. } \\
(\mathrm{ml})\end{array}$ & $\begin{array}{c}\text { Motil. } \\
(\%)\end{array}$ & $\begin{array}{l}\text { Vigor } \\
(0-5)\end{array}$ & $\begin{array}{c}\text { Conc. } \\
\left(\times 10^{6} / \mathrm{ml}\right)\end{array}$ & $\begin{array}{c}\text { Normai } \\
\mathrm{s}(\%)\end{array}$ & $\begin{array}{c}\text { Anormais } \\
(\%)\end{array}$ & $\begin{array}{c}\text { Across. } \\
\text { Integ. }(\%)\end{array}$ & $\begin{array}{l}\text { Vol. } \\
\text { Test. } \\
\left(\mathrm{cm}^{3}\right)\end{array}$ \\
\hline Pré & $\begin{array}{c}0.7 \pm 0 \\
1\end{array}$ & $\begin{array}{c}71.7 \pm 7 \\
9\end{array}$ & $\begin{array}{c}3.5 \pm 0 \\
6\end{array}$ & $2.8 \pm 1.3$ & $\begin{array}{c}62.8 \pm 7 \\
.2\end{array}$ & $\begin{array}{c}37.3 \pm 7 \\
2\end{array}$ & $\frac{67.4 \pm 16}{3}$ & $5.2 \pm 1.2$ \\
\hline Pós & $\begin{array}{c}0.3 \pm 0 \\
2\end{array}$ & $0,0 \pm 0.0$ & $\begin{array}{c}0.0 \pm 0 \\
0\end{array}$ & $4.7 \pm 1.6$ & $\begin{array}{c}61.4 \pm 8 \\
.2\end{array}$ & $\begin{array}{c}38.6 \pm 8 \\
2\end{array}$ & -- & $3.8 \pm 0.8$ \\
\hline Pós & $\begin{array}{c}0.3 \pm 1 \\
8\end{array}$ & $0.0 \pm 0.0$ & $\begin{array}{c}0.0 \pm 0 \\
0\end{array}$ & $0.8 \pm 0.7$ & $\begin{array}{c}77.5 \pm 9 \\
.5\end{array}$ & $\begin{array}{c}22.5 \pm 9 \\
5\end{array}$ & -- & $3.6 \underset{c}{ \pm} 0.7$ \\
\hline Pós & $\begin{array}{c}0.1 \pm 0 \\
0\end{array}$ & $0.0 \pm 0.0$ & $\begin{array}{c}0.0 \pm 0 \\
0\end{array}$ & $0.0 \pm 0.0$ & - - & -- & -- & $4.0 \pm 2.0$ \\
\hline Pós & $0.5 \pm 0$ & $0.0 \pm 0.0$ & $\begin{array}{c}0.0 \pm 0 \\
0\end{array}$ & $0.0 \pm 0.0$ & - - & - - & -- & $5.1 \pm 0.9$ \\
\hline Pós & $\begin{array}{c}0.05 \pm 0 \\
.0\end{array}$ & $0.0 \pm 0.0$ & $\begin{array}{c}0.0 \pm 0 \\
0\end{array}$ & $0.0 \pm 0.0$ & -- & -- & -- & $5.5 \pm 1.1$ \\
\hline
\end{tabular}

Dados não aferidos devido à quantidade insuficiente de espermatozóides para análise.

ablc Letras diferentes indicam diferença significativa $(\mathrm{p}<0.05)$

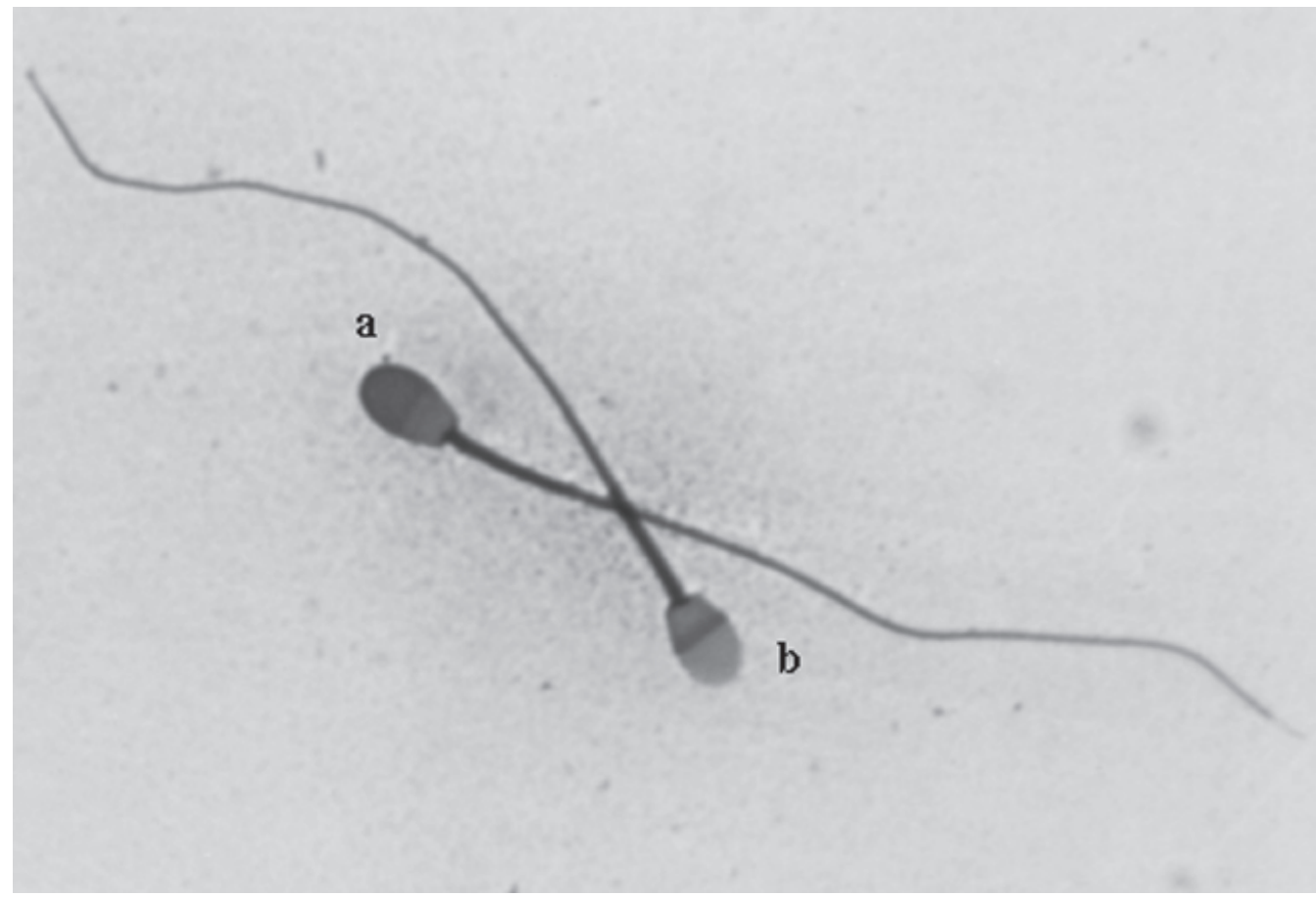

Fig ura 1 - Espermatozóides de Macaco prego (Cebus apella) apresentando acrossoma íntegro/corado (a) e acrossoma lesado/sem coloração (b), segundo Pope, et al. 1991 
abaixo quando comparada aos dados encontrados nos trabalhos anteriores. No entanto, a literatura apresenta poucos trabalhos avaliando sêmen de Cebus apella.

Quanto às anormalidades espermáticas a média encontrada para $C$. apella por Barnabe et $\mathrm{al}^{16} \mathrm{em}$ zoológicos brasileiros foi de $62.86 \%$ diferindo de maneira acentuada dos dados por nos encontrados de $32.8 \%$ com relação às anormalidades espermáticas. No entanto, segundo Harrison e Wolf ${ }^{19}$ primatas não humanos são geralmente tidos como animais que apresentam um ejaculado uniforme com relativamente poucas anomalias.

Em geral a média do volume por ejaculado diminuiu após a vasectomia, esse declínio pode ser atribuído a privação da fração contendo espermatozóides no ejaculado ${ }^{20}$. Esse resultado está de acordo com outros trabalhos realizados em touros e carneiros após vasectomia unilateral ${ }^{21}$ ou bilateral ${ }^{22}$.

Em trabalho semelhante realizado em touros, a motilidade espermática foi observada até sete dias após a vasectomia e a concentração espermática foi drasticamente reduzida após a primeira semana, sendo os animais deste estudo considerados aptos a trabalhar como detectores de cio, sem risco acidental de fecundação, após uma semana da vasectomia ${ }^{3}$.

Neste experimento os animais apresentaram redução na concentração espermática apenas após dois meses da realização da vasectomia. Segundo Janett et al. ${ }^{22}$ os espermatozóides podem ficar acumulados no ducto deferente e nas glândulas sexuais acessórias, diminuindo progressivamente depois de repetidas extrações.

Apesar de não encontrarmos espermatozóides vivos já na primeira colheita após a vasectomia, nossos resultados quanto à concentração espermática sugerem que machos vasectomizados devam voltar ao grupo, sem risco de fecundação acidental, apenas após três meses da realização da vasectomia.

\section{Agradecimentos}

Fundação Parque Zoológico de São Paulo/SP.

\section{Semen characteristics evaluation in capuchin monkey (Cebus apella) in captivity, before and after bilateral vasectomy}

\begin{abstract}
The effects of bilateral vasectomy on the seminal characteristics were assessed in capuchin monkeys (Cebus apella). Six adult male monkeys were housed separately in outdoor pens at the Fundação Parque Zoológico de São Paulo. Semen samples were collected by electroejaculation, after anesthetized the animals, 15 days before and once a month from 1 to 5 months after vasectomy. Immediately after the ejaculation, semen was analyzed for volume $(\mathrm{ml}), \mathrm{pH}$, motility $(\%)$, vigour (0-5), concentration (cells/ml), defects (\%) and percentage of intact acrosoma (\%). The percentage of intact acrossoma was analyzed only in the collection before the vasectomy and the concentration was done in only four males in these collection because have no semen enough for all analyses. One month after the vasectomy ejaculated spermatozoa were non-motilite and non-vigour in all vasectomized males. In addition the Mean/SEM of cells/ml before the vasectomy was $2.8 \pm 1.3 \times 10^{6} / \mathrm{ml}$ and after two months of the vasectomy was $4.7 \pm 1.6 \times 10^{6} / \mathrm{ml}, 0.8 \pm 0.7 \times 10^{6} / \mathrm{ml}$, respectively. Only after the thirty month the number of cells $/ \mathrm{ml}$ was zero. Our results suggest that the vasectomized males may be back to the group, without risks of accidental fecundating, only 3 months after vasectomy.
\end{abstract}

Key-words: Vasectomy. Primates. Sperm. Fertility Control. 


\section{Referencias}

1 FREESE, C. H.; OPPENHEIMER, J. R. The capuchin monkeys, genus Cebus, In: COIMBRA FILHO, A. F.; MITTERMEIER, R. A. Ecology and behavior of neotropical primates. Rio de Janeiro: Academia Brasileira de Ciência, 1981. p. 331-90.

2 MITTERMEIR, R. A; COIMBRA FILHO, A. F. Primate conservation in brazilian amazonia, In: RAINIER, P. BOURNE, G. Primate conservation. New York: Academic Press, 1977. p.117-66.

3 NAGLE, C. A. DENARI, J. H. The reproductive biology of capuchin monkeys (Cebus spp). International Zoo Yerbook, v. 22, p. 143-50, 1982.

4 HILL, W. C. O. Primate: comparative anatomy and taxonomy. Edinburgh: Edinburg at the University Press, 1960, v.4

5 NAPIER, J. R.; NAPIER, P. H. The natural history of the primates, Cambridge: The MIT Press, Structure and Function, 1986. p. 30-59,

6 HAMLETT, G. W. D. Reproduction in american monkeys, estrous cycle, ovulation and menstruation in Cebus. Anatomical Record, v. 73, p. 171-87, 1939.

7 SOCIEDADE DE ZOOLÓGICOS DO BRASIL SZB / CENSO 2003. Disponível em: http://www.bdt.fat.br/ zoo/zooplantel/. Acesso em: 05 marc. de 2004.

8 SAPOLSKY, R. M.; KREY, L. C. Stress-induced suppression of luteinizing hormone concentration in wild baboons: role of opiates. Journal of Clinical Endocrinology and Metabolism, v. 66, n. 4, p. 722-6, 1988.

9 HADLEY, M. A.; DYM, M. Spermatogenesis in the vasectomized monkey: quantitative analysis. The Anatomical Record, v. 205, p. 381-386, 1983.

10 PENGE, B. et al. Quantitative (stereological) study of the effects of vasectomy on spermatogenesis in rhesus monkeys (Macaca mulatta). Reproduction, v. 124, p. 847-856, 2002.

11 GUIMARÃES, A. B. V. Contribuição para o estudo da colheita e avaliação do sêmen do macaco prego Cebus apella (Erxleben, 1777). Dissertação (Mestrado em Reprodução Animal) - Faculdade de Medicina Veterinária e Zootecnia: Universidade de São Paulo, São Paulo, 1994.

12 BLOM, E. On the evaluation of bull semen with special reference to the employment for artificial insemination. Thesis - Copenhage, 1950.

13 POPE, C. E.; ZHANG, Y. Z.; DRESSER, B. L. A simple staining method for evaluating acrossomal status of cat spermatozoa. Journal of Zoo and Wildlife Medicine, v. 22, n.1, p. 87-95, 1991.

14 JOHSTON, L. A; ARMSTRONG, D. L., BRONW,
J.L. Seasonal effects on seminal and endocrine traits in the captive snow leopard (Panthera uncia). Journal of Reproduction and Fertility, v. 102, n. 1, p. 229-236, 1994.

15 STATISTIC ANALISYS SYSTEM. SAS user's guide: statistics. Cary: SAS, 1999.

16 BARNABE, R. C. et al. Análise de alguns parâmetros normais do espermograma de macaco-prego. (Cebus paella, Linnaeus, 1758), Brazilian Journal Veterinarian Animals Science, v. 39, n. 6, p. 331-333, 2002.

17 BUSH, D. E.; RUSSEL, L. H.; FLOWERS, A. I.; SORENSEN, A. M. Semen evaluation in capuchin monkey (Cebus apella). Laboratory Animal Science, v. 25, p. 588-593, 1975.

18 ROUSSEL, J. D.; AUSTIN, C. R. Improved electroejaculation of primates. Journal of he Institute of Animal Technicians, v. 19, n. 1, p. 22-32, 1968.

19 HARRISON, R. M.; WOLF, R. H. Sperm parameters and testicular volumes in saguinus mystax. Journal of Medical Primatology, v. 14, p. 281-284, 1985.

20 BATISTA, M. et al. Semen characteristics and plasma levels of testosterone after bilateral vasectomy in bucks. Reproduction Dom Animal, v. 37, p. 375-378, 2002.

21 AHMAD, N.; NOAKES, D. E. A clinical and ultrasonographic study of the testes and related structures of goats and rams after unilateral vasectomy. Veterinary Record, v.137, p.112-117, 1995.

22 JANETT, F. et al. Semen characteristics after vasectomy in the ram. Theriogenology, v. 56, p. 485-491, 2001. 